\title{
Teratogenic effect in the gas gland of fish induced by the fabric softener ditallow dimethyl ammonium chloride
}

\author{
P. W. Wester ${ }^{1}$, C. J. Roghair ${ }^{2}$ \\ ${ }^{1}$ Laboratory for Pathology, National Institute of Public Health and Environmental Protection, PO Box 1, 3720 BA Bilthoven, \\ The Netherlands \\ ${ }^{2}$ Laboratory for Ecotoxicology, National Institute of Public Health and Environmental Protection, PO Box 1, 3720 BA \\ Bilthoven, The Netherlands
}

\begin{abstract}
The effect of the cationic surfactant ditallow dimethyl ammonium chloride (DTDMAC, the active compound in fabric softeners) was studied in 2 small fish species, Oryzias latipes (medaka) and Gasterosteus aculeatus (three-spined stickleback). The fish were exposed to increasing concentrations of the compound from 0.32 up to $5.6 \mathrm{mg} \mathrm{l}^{-1}$, starting from the egg stage, for $56 \mathrm{~d}$ (medaka) and $45 \mathrm{~d}$ (stickleback), after which they were examined histopathologically. There was increased mortality in the $\geq 1.8 \mathrm{mg} \mathrm{l}^{-1}$ groups of $O$. latipes and in the $\geq 3.2 \mathrm{mg} \mathrm{l}^{-1}$ groups of $G$. aculeatus. Abnormal swimming was observed in the $\geq 0.56 \mathrm{mg} \mathrm{l}^{-1}$ groups of $O$. latipes and in the $\geq 1.0 \mathrm{mg} \mathrm{l}^{-1}$ groups of $G$. aculeatus. Histopathological examination of the surviving fish showed the swimbladder to be similarly affected in both species; changes included the absence of the bladder lumen, with epithelial dysplasia, resulting in an ineffective bladder. An associated change was the persistence of the pneumatic duct. In medaka, the gills were also affected with hyperplasia of epithelium, including chloride cells. It is concluded that DTDMAC may have teratogenic potential in fish
\end{abstract}

\section{INTRODUCTION}

Ditallow dimethyl ammonium chloride (DTDMAC) is one of the most important cationic surfactants used as fabric softener (Lewis \& Wee 1983). It is an industrial product that may contain impurities such as trialkyl ammonium compounds (Consultative Expert Group Detergents-Environment 1988); its degradation in sewage treatment plants is not complete, and its fate and toxicity for aquatic life are matters of concern for regulatory authorities (Van Leeuwen et al. 1990, in press). Accordingly, this paper describes the histopathological effects of long-term DTDMAC exposure in medaka Oryzias latipes and three-spined stickleback Gasterosteus aculeatus, 2 species which we now routinely use in toxicology trials at our institute.

\section{MATERIAL AND METHODS}

Test substance and solutions. A batch of technicalgrade DTDMAC was obtained from Procter \& Gamble,
Strombeek, Belgium. The test substance consisted of $77 \%$ DTDMAC, $1.7 \%$ monotallow trimethyl ammonium chloride (MTTMAC) and $13.3 \%$ isopropanol dissolved in water.

Due to the adsorptive properties of DTDMAC, all glassware used was rinsed with $99 \%$ chloroform and $99 \%$ methanol, and prepared with a DTDMAC solution before use. During the experiments glassware was rinsed with demineralized water only.

Stock solutions of the test substance were freshly prepared before use. A small batch of DTDMAC was liquified in a water bath $\left(50^{\circ} \mathrm{C}\right)$ and homogenized prior to weighing. Then it was diluted with water and stirred for ca $15 \mathrm{~min}$.

Test organisms. Oryzias latipes and Gasterosteus aculeatus were reared in the Laboratory for Ecotoxicology of our institute in 'Dutch standard water' (DSW; distilled water containing, per liter, $100 \mathrm{mg} \mathrm{NaHCO}$, $20 \mathrm{mg} \mathrm{KHCO}_{3}, 200 \mathrm{mg} \mathrm{CaCl}_{2} \cdot \mathrm{H}_{2} \mathrm{O}$ and $180 \mathrm{mg}$ $\mathrm{MgSO}_{4} \cdot 7 \mathrm{H}_{2} \mathrm{O}$; hardness was $210 \mathrm{mg} \mathrm{CaCO} \mathrm{l}^{-1}$ ). Oxygen levels were above $6.0 \mathrm{mg}^{-1}$, and $\mathrm{pH}$ was between 7.4 and 8.6. Adult fish were fed daily with frozen 
Artemia salina and commercial fish food. Trouwvit (Trouw \& Co., Putten, The Netherlands) and, in addition Tetraphyll (Tetra Werke, Ulrich Baemsch GmbH, Melle, Germany) for medaka. Young fish were fed Branchionus rubens, A. salina and commercial fish food (Trouwvit, Tetraphyll).

Experiments. The tests were initiated with freshly fertilized eggs $(<24$ and $<6 \mathrm{~h}$ for medaka and stickleback respectively), 25 in each experimental group. The test organisms were exposed to nominal concentrations of $0.32,0.56,1.0,1.8$ or $5.6 \mathrm{mg} \mathrm{l}^{-1}$. In each experiment a control group was used, which differed from the exposed groups only in that no DTDMAC was added to the dilution water. In order to mimic the bioavailability of DTDMAC under natural conditions, the diluent for stickleback was filtered water $(50 \mu \mathrm{m})$ from Lake IJssel, since DTDMAC adsorbs to organic material and is neutralized by anionic compounds. In the medaka experiment DSW was used because of high mortality among the eggs when using Lake IJssel water. The test solutions were renewed 3 times a week, and the total exposure period was 56 and $45 \mathrm{~d}$ for the medaka and sticklebacks respectively. Water temperature for the sticklebacks was $19 \pm 1^{\circ} \mathrm{C}$ and for the medaka $23 \pm 2^{\circ} \mathrm{C}$. Fish were fed once daily. For the first few days they were fed Branchionus rubens, then Artemia salina nauplii and finally dry food (Tetramin, Tetraphyll). Oxygen concentration and $\mathrm{pH}$ were measured at least once weekly, and observations on mortality and sublethal effects were made 3 times per week

At the end of the exposure period the fish were killed by an overdose of anesthesia (MS222) and fixed in Bouin's. Ten fish from each group were, in toto, processed routinely for paraffin wax embedding. Serial sections $(5 \mu \mathrm{m})$ were cut at 10 to 15 levels and stained with haematoxylin and eosin (H\&E). From some remaining medaka from the $1 \mathrm{mg}^{-1}$ group, serial transverse sections were cut in order to study the swimbladder lesions in perpendicular orientation.

\section{RESULTS}

Increased mortality in the medaka occurred at a nominal concentration of $1.8 \mathrm{mg} \mathrm{l}^{-1}$ and higher. Abnormal swimming (staggering and preference for the lower water column) was observed from $0.56 \mathrm{mg}^{-1}$ onwards. In sticklebacks increased mortality was observed at nominal concentrations of 3.2 and $5.6 \mathrm{mg} \mathrm{l}^{-1}$. whereas abnormal swimming (staggering) occurred from $1.0 \mathrm{mg} \mathrm{l}^{-1}$ onwards.

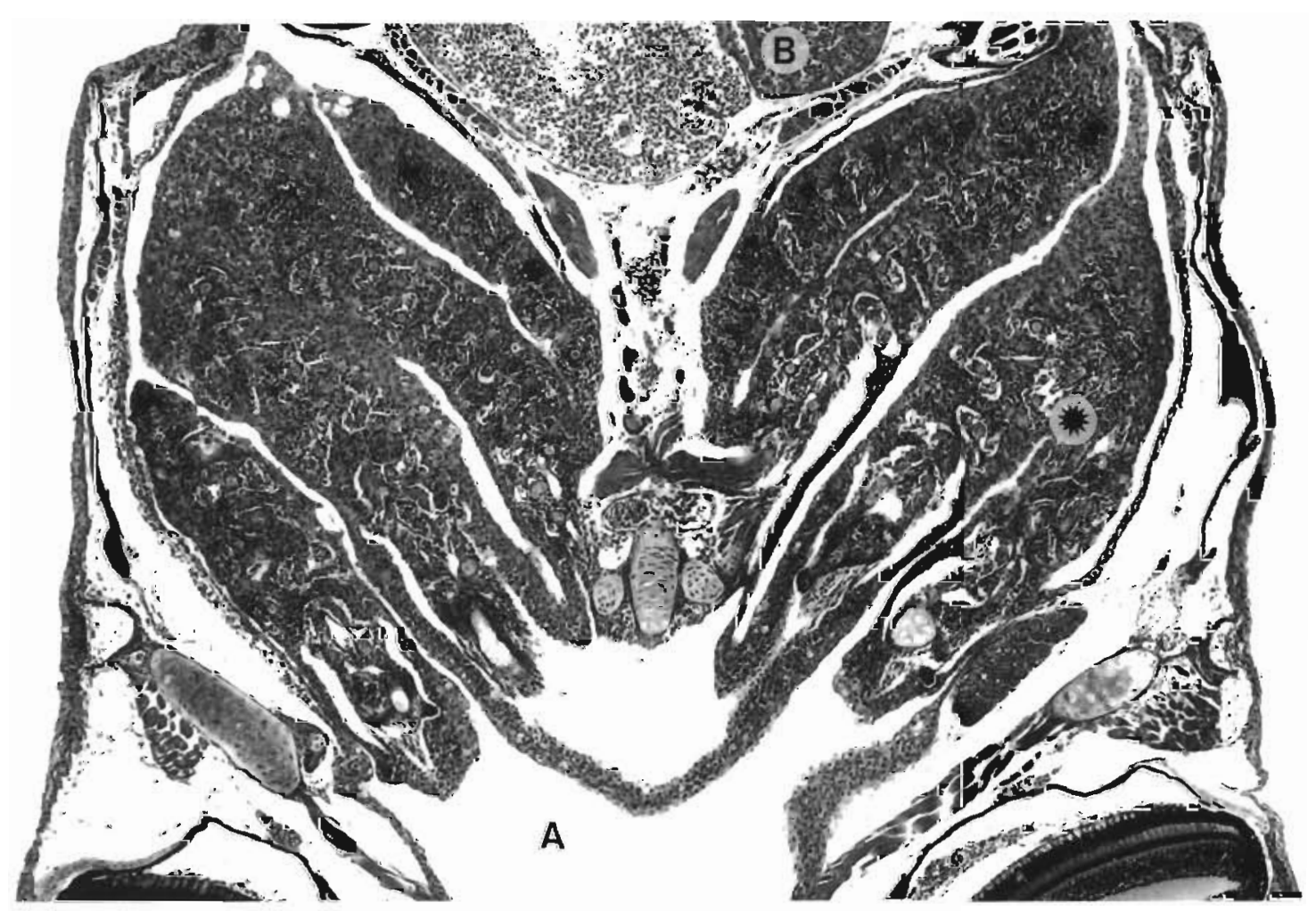

Fig. 1. Oryzias latipes. Gill section of medaka $\left(1.8 \mathrm{mg}\right.$ DTDMAC $\left.\mathrm{l}^{-1}\right)$. A: Oral cavity; B: heart. Note obliteration of interlamellar spaces and fusion of lamellae (asterisk). $H \& E, \times 100$ 
Table 1. Oryzias latipes and Gasterosteus aculeatus. Prevalence of histopathological lesions in medaka and stickleback exposed to DTDMAC

\begin{tabular}{|c|c|c|c|c|c|c|}
\hline DTDMAC $\left(m g l^{-1}\right)$ : & 0 & 0.32 & 0.56 & 1.0 & 1.8 & 3.2 \\
\hline \multicolumn{7}{|l|}{ O. latipes } \\
\hline No. examined & 10 & 10 & 10 & 10 & 5 & \\
\hline Gas gland dysplasia & & & 5 & 9 & 5 & \\
\hline \multicolumn{7}{|l|}{ Gill hyperplasia } \\
\hline Moderate & & & 4 & & & \\
\hline Marked & & & & 10 & 5 & \\
\hline \multicolumn{7}{|l|}{ G. aculeatus } \\
\hline No. examined & 10 & 10 & 10 & 10 & 10 & 1 \\
\hline Gas gland dysplasia & & & & & 8 & 1 \\
\hline
\end{tabular}

Histopathological effects were found in swimbladders, at $0.56 \mathrm{mg}$ DTDMAC $\mathrm{l}^{-1}$ and higher for medaka and 1.8 and $3.2 \mathrm{mg} \mathrm{I}^{-1}$ for sticklebacks (Table 1).

The gills were affected in medaka only (from 0.56 $\mathrm{mg}^{\mathrm{l}^{-1}}$ onwards). Changes were characterized by hyperplasia of lamellar epithelium, including chloride cells, and some inflammatory cell infiltration (Figs. 1 \& 2).

The swimbladder in unaffected fish is a thin-walled hollow organ within the abdominal cavity, with a disklike glandular structure at the cranial (medaka) or lateral wall (stickleback) (Fig. 3). Blood is supplied by a vascular rete that originates from the coeliacomesenteric artery. In close association with this rete some ganglion cells can be found, indicating a supply of regulatory nerves. In affected fish the swimbladder consisted of a globular solid epithelial structure with no or only an inconspicuous and irregular lumen (Figs. 4 to 6 ). The epithelial cells were hyperplastic, irregular in size and frequently hypertrophic, with many cells showing polymorphous and atypical nuclei (large nuclei and nucleoli, multinucleated cells, convoluted nuclei, etc.). Based on these features, such glands were considered dysplastic. In and around dysplastic gas

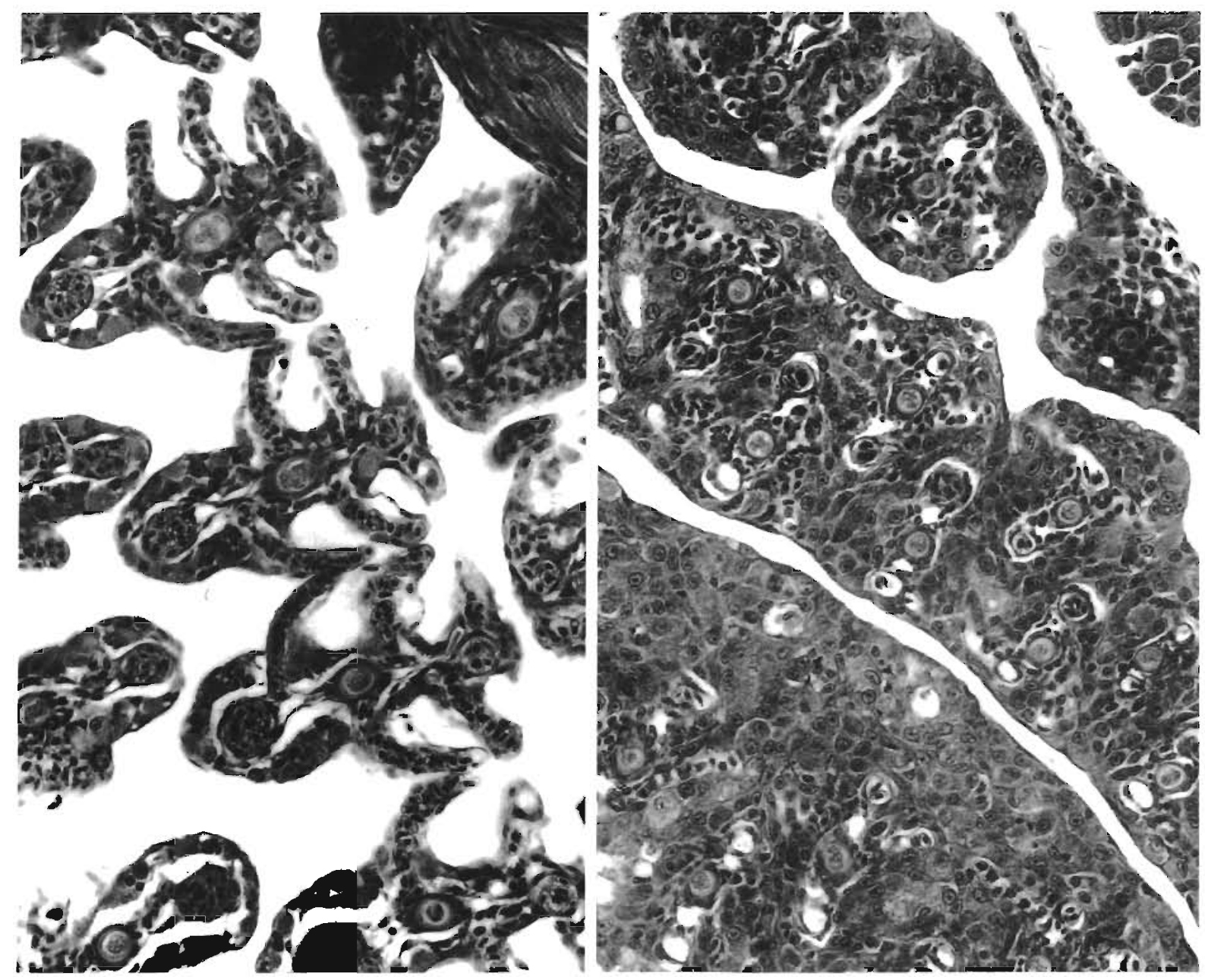

Fig. 2. Oryzias latipes. Detail of gill lamellae of control (left) and $1.0 \mathrm{mg} \mathrm{DTDMAC} \mathrm{I}^{-1}$ exposed medaka (right). There is extensive epithelial hyperplasia, causing fusion of lamellae and reduction of respiratory surface. H\&E, $\times 400$ 


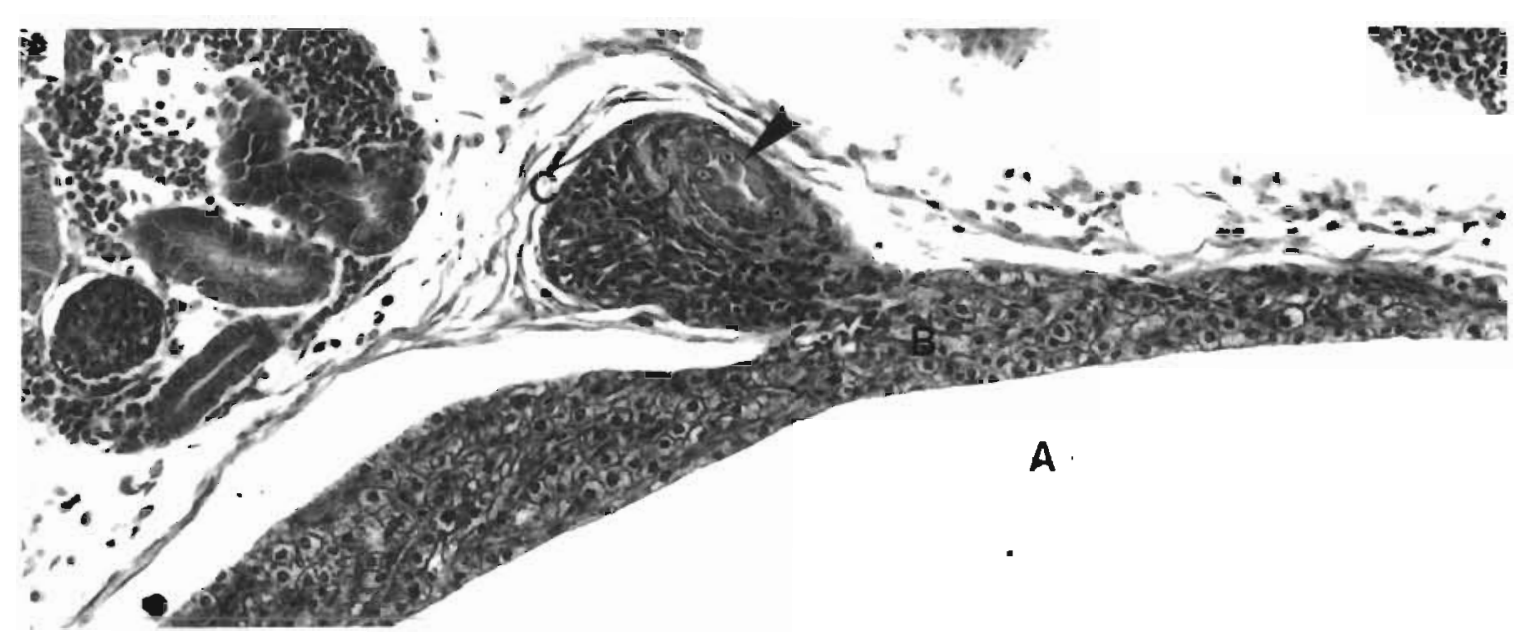

Fig. 3. Oryzias latipes. Swimbladder of medaka exposed to $1.0 \mathrm{mg}$ DTDMAC $1^{-1}$. A: Lumen; B: gas gland; C: rete mirabile. This gland is unaffected, but the rudimentary pneumatic duct is clearly visible (arrowhead). H\&E, $\times 250$

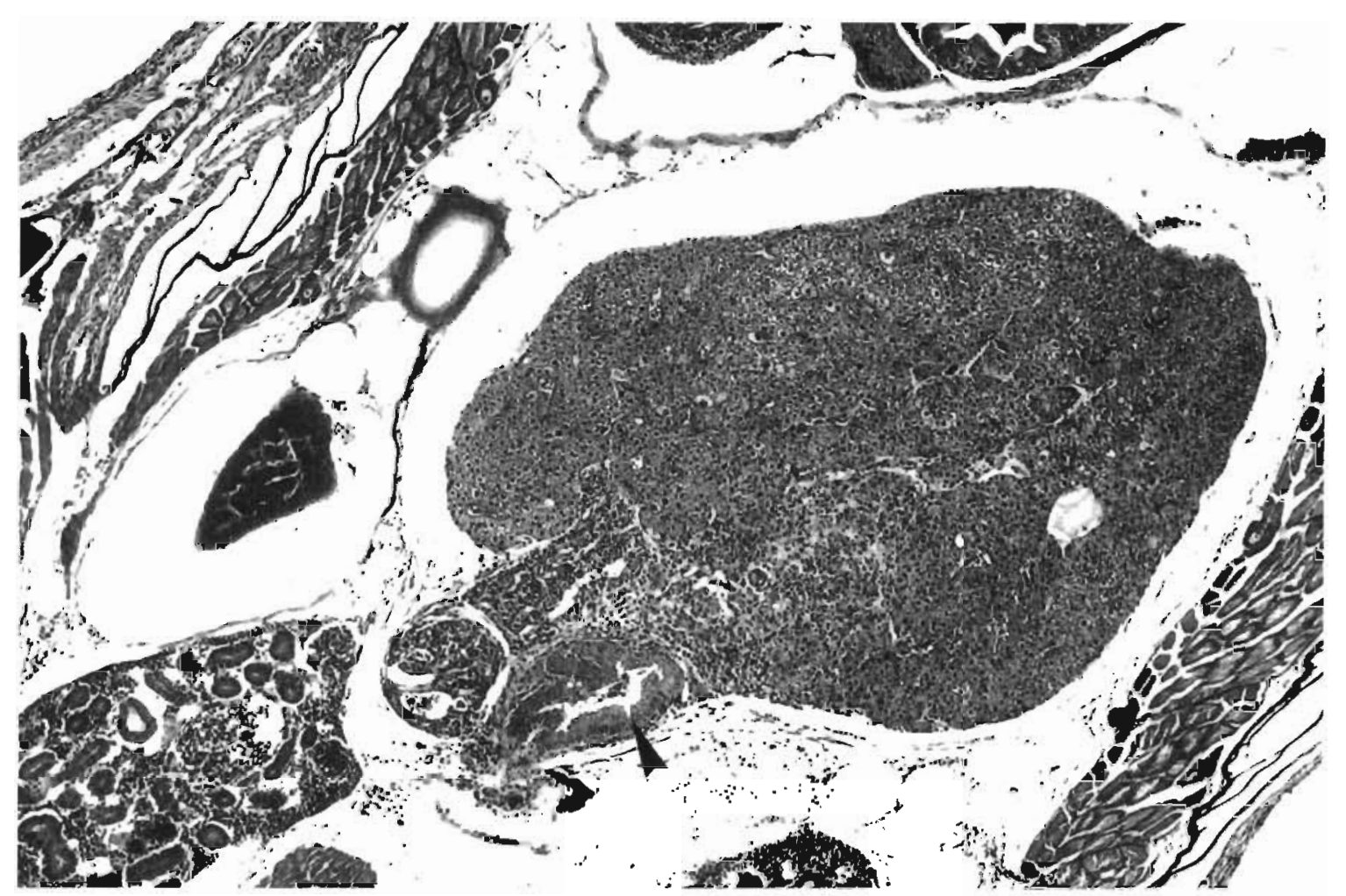

Fig. 4. Oryzias latipes. Low-power view of DTDMAC-exposed medaka $\left(0.56 \mathrm{mg} \mathrm{l}^{-1}\right)$. Dysplastic 'swimbladder', consisting of the gas gland appearing as a pear-shaped solid hyperplastic organ with, near the vascular stalk, a clear tubular structure (prosoplastic pneumatic duct; arrowhead) connecting the gas gland with the intestinal mucosa (not visible). H\&E, $\times 100$

glands foamy cells, possibly macrophages, could be found, along with lymphocytes and some debris (Figs. $5 \& 6)$

The vascular stalk was slightly tortuous in sticklebacks, and the accompanying ganglion cells were hypertrophic and had large hyperchromatic nuclei
(Fig. 6). A striking feature was the presence of a tubular epithelial structure accompanying the vascular stalk and sometimes reaching into the center of the gland (Fig. 6). This tubular structure was observed in medaka only and was composed of cuboidal to columnar epithelium with a clear lumen, sometimes partially 


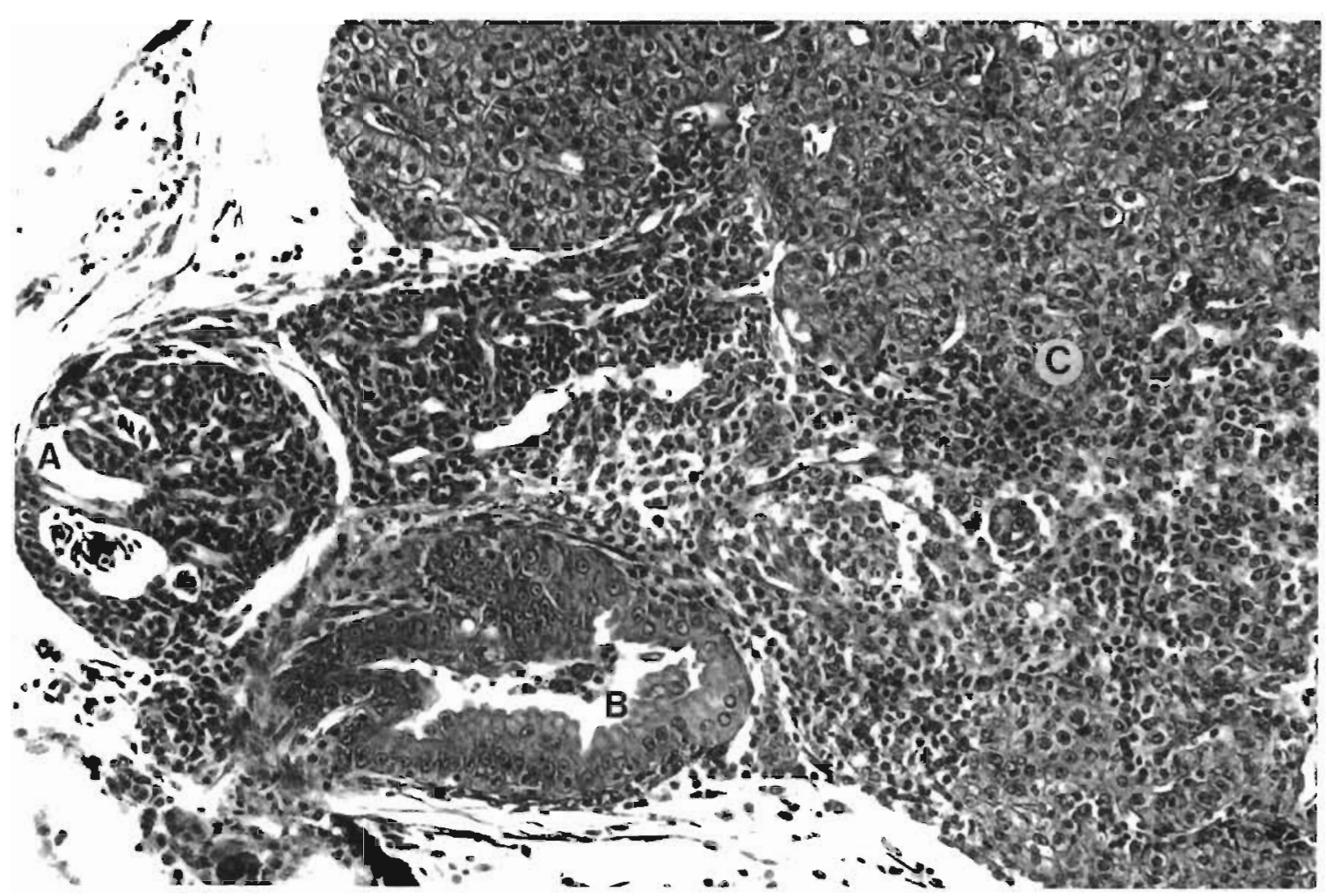

Fig. 5. Oryzias latipes. Detail of dysplastic gas gland in Fig. 4. A: Rete mirabile: B: hyperplastic (prosoplastic) pneumatic duct with inflammatory cells and debris in its lumen; C: hyperplastic gas gland with heterogeneous cell population, including inflammatory cells. H\&E, $\times 250$

filled with cellular debris (Figs. 4 \& 5). In appropriate longitudinal sections and in particular in the serial transverse sections of medaka, it was seen that this tubular structure penetrated the pharyngeal/esophageal wall and was continuous with its mucosa. Occasionally this tubular structure was found without the swimbladder changes described above (Fig. 3). In sticklebacks, no such tubular structure could be discerned.

\section{DISCUSSION}

The most notable finding in this study was the swimbladder anomaly occurring at nominal concentrations of $\geq 0.56$ and $\geq 1.8 \mathrm{mg} \mathrm{l}^{-1}$ for medaka and stickleback respectively. The abnormal swimming behaviour observed is easily explained as a result of defective gas bladders, in particular in the medaka, which remained at rest in the lower water column. Altered swimbladders were characterized by abnormal differentiation or dysplasia of the gas gland and the absence of an inflated lumen. Initial inflation of the gas bladder is accomplished by gulping air from the environment, at least in stickleback (Lagler et al. 1962) and probably also in medaka, as suggested by the presence of an open pneumatic duct in larval stages. It is suspected that the abnormal differentiation of the gas gland, which is then incapable of forming a lumen, is the underlying pathogenesis, rather than the inability to gulp air. Later on the gas gland produces gas by releasing blood gases after decreasing the $\mathrm{pH}$ of the afferent blood, at least in euphysioclists (Fänge 1953), such as medaka and stickleback. The hyperplastic and hypertrophic changes in the gas gland epithelium and the activated morphology of the ganglion cells suggest a hyperstimulation, possibly to compensate for the ineffective organ.

Failure of the swimbladder to inflate has been reported recently by Marty et al. (1990) after pulse exposure of medaka eggs to carcinogenic nitroso compounds. In that study, however, no histological description was given, and this change, considered as teratological, was observed in hatchlings only. DTDMAC as used in the present study belongs to a different chemical class and has not yet been studied for carcinogenicity.

The chemical basis of the effect observed in the present study remains unknown; comparative studies with related and unrelated surface-active compounds could be helpful in further characterizing the mechanism. Since a technical-grade product was studied here, it is 


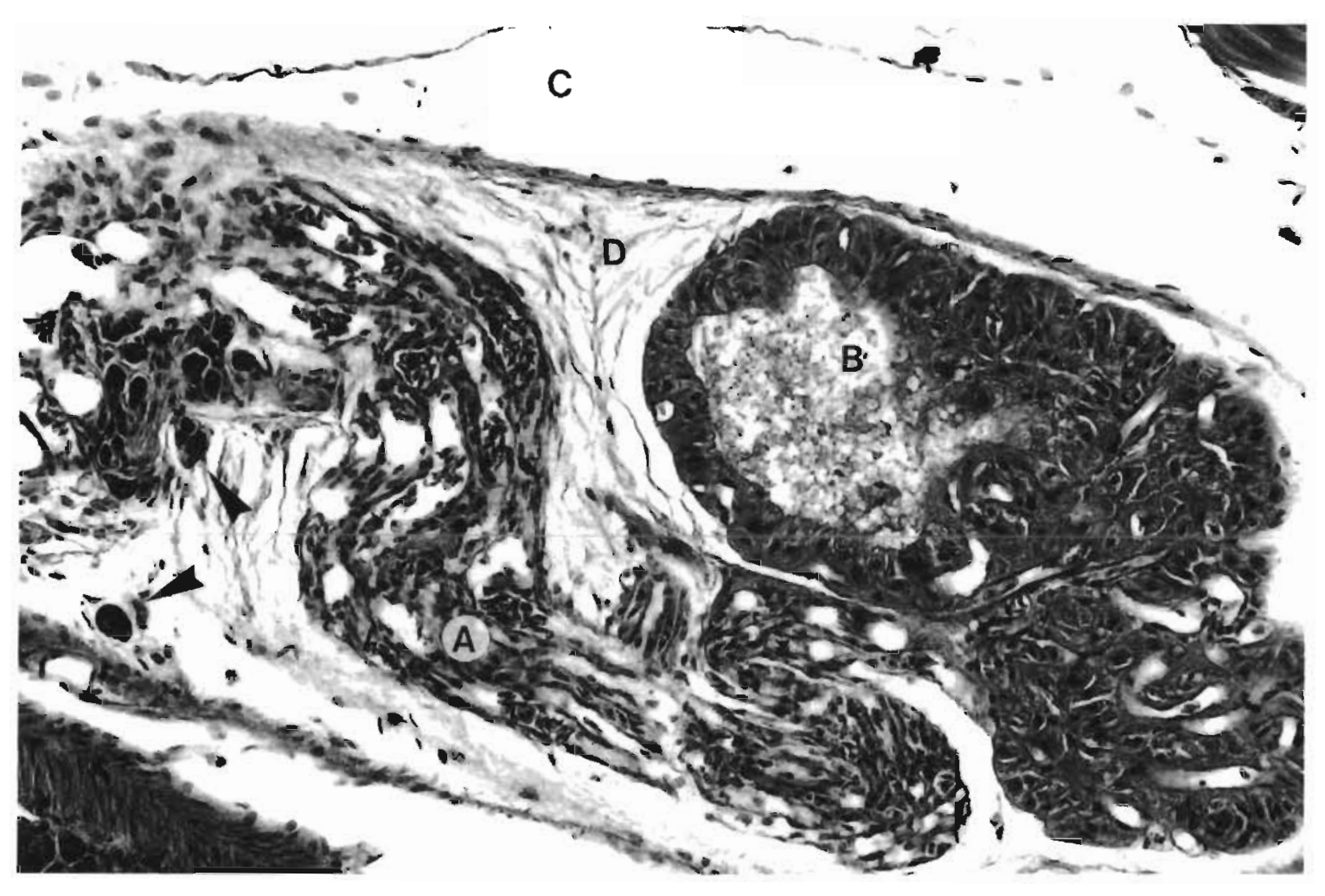

Fig. 6. Gasterosteus aculeatus. Dysplastic gas gland of stickleback exposed to $1.8 \mathrm{mg}$ DDMAC $1^{-1}$. Arrowhead: Hypertrophic ganglion cells; A: tortuous rete mirabile with dilated capillaries; B: undeveloped lumen containing debris; C: body cavity; $D$ : retroperitoneum. Note absence of pneumatic duct. $H \& E_{1} \times 250$

not clear whether the effects were caused by the major ingredient (DTDMAC) or by contaminants. The occurrence of this effect in 2 unrelated species suggests a uniform mechanism across fish families. Therefore it would also be of interest to study these compounds in other (mammalian) species with emphasis on teratogenicity and, in view of the hyperplasia and dysplasia, for carcinogenicity.

The gill changes include hyperplasia of both the squamous epithelium and the chloride cells. These are considered to be nonspecific lesions, as observed for a wide variety of waterborne stressors (Mallatt 1985), but they are not common after long-term nonlethal exposures to toxic chemicals (Wester 1988, Wester et al. 1988).

Although the abnormalities described may have serious ecological implications, the actual concentrations in the environment 2 to $90 \mu \mathrm{gl}^{-1}$, as measured in The Netherlands and Germany (Van Leeuwen et al. 1990, in press)] are in general below the effective nominal concentrations in this experiment. Based on exposure assessment, concentrations of more than $100 \mu \mathrm{g}^{-1}$ can be expected in smaller-area surface waters (Van Leeuwen et al. unpubl.). For regulatory purposes, this study demonstrates the margin between effective and environmental concentrations of this component in fabric softeners.

Acknowledgements. The authors thank D. Gielen for animal care, A. Buijze and J. Hoekman for skillful technical assistance and Drs J. G. Vos and H. A. M. de Kruijf for comments on the manuscript

\section{LITERATURE CITED}

Consultative Expert Group Detergents-Environment (1988). Environmental aspects of the use of cationics as fabric softeners. Nota I. Consultative Expert Group DetergentsEnvironment, Utrecht (in Dutch)

Fänge, R. (1953). The mechanism of gas transport in the euphysioclist swim bladder. Acta physiol. Scand. 30 (Suppl.) 11.0: $1-133$

Lagler, K. F., Bardach, J. E., Miller, R. (1962). The gas bladder as a hydrostatic organ. In: Ichthyology. John Wiley \& Sons, New York, p. 251-258

Lewis, M. A., Wee, V.T (1983). Aquatic safety assessment for cationic surfactants. Envir. Toxic. Chem. 2: 105-118

Mallatt, J. (1985). Fish gill structural changes induced by toxicants and other irritants: a statistical review. Can. J. Fish. Aquat. Sci. 42: 630-648 
Marty, G. D., Nunez, J. M. D., Lauren, J., Hinton, D. E. (1990). Age-dependent changes in toxicity of $\mathrm{N}$-nitroso compounds to Japanese medaka (Oryzias latipes) embryos. Aquat. Toxicol. 17: 45-62

Van Leeuwen, K., Roghair, C. J., De Greef, J., De Nijs, T (1990). New facts about fabric softeners. $\mathrm{H}_{2} \mathrm{O}$ 23: 295-299 (in Dutch)

Van Leeuwen, K., Roghair, C. J., De Nijs, T., De Greef, J. (in press). Ecotoxicological risk evaluation of the cationic fabric

Responsible Subject Editor: G. Peters, Hamburg, Germany softener DTDMAC. IIl: Risk assessment. Chemosphere Wester, P. W. (1988). Toxicological pathology in fish: an evaluation with two species and various environmental contaminants. Ph.D. thesis, University of Utrecht

Wester, P. W. Canton, J. H. Dormans, J A. M. A. (1988). Pathological effects in freshwater fish Poecilia reticulata (guppy) and Oryzias latipes (medaka) following methyl bromide and sodium bromide exposure. Aquat. Toxicol 12: $323-344$

Manuscript first received: April 10, 1991

Revised version accepted: December 30, 1991 